\title{
OUTBOUND SUPPLY CHAIN COLLABORATION MODELLING BASED ON THE AUTOMOTIVE INDUSTRY
}

\author{
Aurimas Vilkelis ${ }^{1,2}$, Sergej Jakovlev ${ }^{3}$ \\ ${ }^{1}$ Dept of Transport Management, Vilnius Gediminas Technical University, Lithuania \\ ${ }^{2}$ Institute for Transport Planning and Systems (IVT), ETH Zurich, Switzerland \\ ${ }^{3}$ Dept of Informatics Engineering, Klaipeda University, Lithuania
}

Submitted 4 March 2013; accepted 21 March 2013 ; first published online 22 May 2013; updated 3 April 2014

\begin{abstract}
The global financial crisis has highlighted shortcomings of logistics operations of many manufacturers. In Europe, the largest share of cargo is transported by road transport, where empty running accounts for about $27 \%$. The statistical result reflects the inefficient use of transportation resources. Today it may be difficult to imagine the whole distribution chain of automobiles manufactured in Europe that would integrate all manufacturers. Nevertheless, in an effort to diminish the shortcomings of transport operations, automotive manufacturers and Logistics Service Providers (LSP) should pay more attention to logistics cooperation. The article presents the specific features of distribution networks of vehicles manufactured in Europe, also providing a scenario of integrating finished vehicle output of different vehicle manufacturers in a single distribution network. The demand for transport resources and efficiency of use of the resources was established according to the scenario. This article is a contribution and a fresh look at the variety of the solutions of transportation problems in modern European automotive industry.
\end{abstract}

Keywords: transportation problem, supply chain, automotive industry, modelling, logistics.

Reference to this paper should be made as follows: Vilkelis, A.; Jakovlev, S. 2014. Outbound supply chain collaboration modelling based on the automotive industry, Transport 29(2): 223-230. http://dx.doi.org/10.3846/16484142.2013.789980

\section{Introduction}

It makes no difference to the end customer whether products of one manufacturer are delivered together with the production of another brand manufacturer. Consequently, there are no reasons to tie transport mean to the product manufacturer, from the end customer's point of view, in an effort to emphasize its exclusivity and cover the additional costs caused by irrational use of transportation resources. As an example, we should think of consumer behaviour in grocery stores when people take a shopping basket or a shopping cart for their purchases. In this case, the shopping basket or cart stands for transport mean intended to carry products of different manufacturers. If clients had to separately go to the cash register to pay for products of each manufacturer and then return to the store for items of a different manufacturer, they would probably refuse to come back to the store ever again. Therefore, based on this example, a production distribution network was worked out where different automobile manufacturers are participants of a unified distribution network with no emphasis on their uniqueness. Nearly every industry is faced with a certain degree of seasonality or erratic need for production, therefore, the loading of the trans- port infrastructure changes accordingly (Ba et al. 2009). Production plans fitted to the sales forecasts made by automobile vendors do not always correspond to the factual situation of the whole year (Tang et al. 2010). In case of the global financial crisis at the end of 2008, a decrease in realization led to accumulation of surplus production, which stacked up terminals of production factories, as well as inland terminals and ports. Consequently, intensity of production and supply chains must be highly dynamic to be able to rapidly respond and adapt to the existing changes in the market. Intensified global competition has led automakers to attempt to institute a 'build-to-order' approach to fulfilment, in which consumers are able to define the characteristics of the vehicles before they are produced. In the more traditional and still prevalent 'build-to-forecast' approach, production is based on forecasts of demand and information received from dealers about prior sales. The time from order to delivery takes on an average of 40 days, of which only $60 \mathrm{~h}$ are used for production; $85 \%$ of the time is accounted for by scheduling and parts sequencing requirements, rather than on the physical product flow (Sturgeon et al. 2009). Proper coordination of the manufacturer's inbound and outbound logistics that 
covers optimization of the supply chain is a crucial factor in reducing the amount of stock and ensuring faster response to client orders. Many manufacturers and LSP who provide solutions for regional or national levels are unable to ensure efficiency of global solutions. Up until now, LSP was the link between different outbound supply chains of automotive manufacturers. However, carriers today are not capable of ensuring efficient service of logistics chains of two or more different automotive manufacturers by adapting to their unique management structures of their supply chains. Due to this reason, the logistics of the future cannot be built on individual concepts. The model of transport flows provided in the article covers European automotive factories and terminals. An analysis of the potential of logistics cooperation among different automotive manufacturer does not highlight the unique logistics features of every manufacturer. All manufacturers in the model are participants of a unified supply network. The objective of the research is to identify problematic geographical points of road transport with a large factor of empty running. To achieve this goal, all automotive manufacturers in this model have stated solidarity to the terms and conditions of this concept. In most cases, transport problems are solved by various mathematical methods, however, there is no unified method for handling specific transport problems. Therefore, many tasks of this type are solved by applying the condition of classic transport problem, with additional unique constraints characteristic of an individual problem.

\section{Literature Review}

In recent years, a decent number of researches were made that analysed complex applications of the classical transportation problem with many additional constraints. These complex transportation problems have been studied extensively for applications ranging from various engineering problems, to simple everyday objectives like postal services and public transportation and finally automotive industry.

Fig. 1 provides a short overview of most recent scientific research of the described problems. Here in a 2 axis diagram, the main scientific research scenario is presented that describes the flow of research development of the presented problem area. In many cases, the achieved results indicate that classical solutions require additional adjustments in order to provide the optimum values.

\section{Background for Outbound Supply Chain Collaboration}

In many cases, insufficient cooperation causes automotive manufacturers to incur enormous losses in the management of the distribution network that are related to changes in supply channels of different manufacturers and the supply of transport resources. With well-established cargo transportation flows, it is vital to establish whether certain transformations of the distribution network, if such are made, may diminish the supply of transport. Strategy of every manufacturer must envisage and assess the intensity of transport flows and the possibilities to attract carriers to his distribution arteries to avoid a deficit of transport supply in case of a rise in transportation volumes. Cooperation of logistics companies in the supply chain is a difficult task, although many studies and researches emphasize a number of advantages. A possible reason may lie in the fact that a supply chain has never been thoroughly expressed in respect of individual production or factories. In practice, supply chain talks among logistics companies or manufacturers lack efficiency because not all parties concerned reveal the unique and specific features of their supply chains.

To solve the problem, every party should have a clear vision of the perspectives and possible benefits of the general supply chain. Implementation of management concept of supply chains of a few companies in many cases revealed the complexity of the concept and merely a few companies managed to achieve the expected effect in the supply chain management environment. Achieving the implementation efficiency of such general logistics concept takes a considerable amount of time to secure positive effects, such as smaller amounts of stock, raw materials and returned production, and the amount of necessary resources on the supply chain. Integrating new processes that have not been verified as well-functioning elements into an established and operational supply chain of a logistics operator or manufacturer is a difficult task.

Complexity of supply chains depends on the scope of the production that needs to be distributed, features of geographic distribution, and elements of logistics infrastructure, such as numbers of different types of transport, terminals and ports. Identification of existing problems of the distribution network (empty running, partial loading, surplus of production in warehouses, damage factor, etc.) is the first step towards forming the general purpose of the concept. There can be no universal model of logistics cooperation that would be suitable for all logistics and production companies. In most cases, such models are only described after being adapted in practice and are functional, in the opposite case, they remain a concept on the paper.

The 3DayCar Logistics Study accentuates that many automotive manufacturers tend to restrict the transportation of their production together with the output of another manufacturer (brand name) on an informal level. The official reasons behind these restrictions are different fastening and transportation requirements of different manufacturers (Holweg et al. 2001). The Association of European Vehicle Logistics (ECG, $h t t p: / /$ ecgassociation.eu) has initiated the creation of uniform rules for automobile transportation, fastening and warehousing for road, railway and sea transport. Nevertheless, it was observed that not all manufacturers approved the unified standards. The uniqueness of the automotive industry lies in the extremely broad use of railway transport in distribution networks.

Different imports and export flows between countries can create badly-connected transport regions, leading to trains and trucks being sent back empty. Sea and 


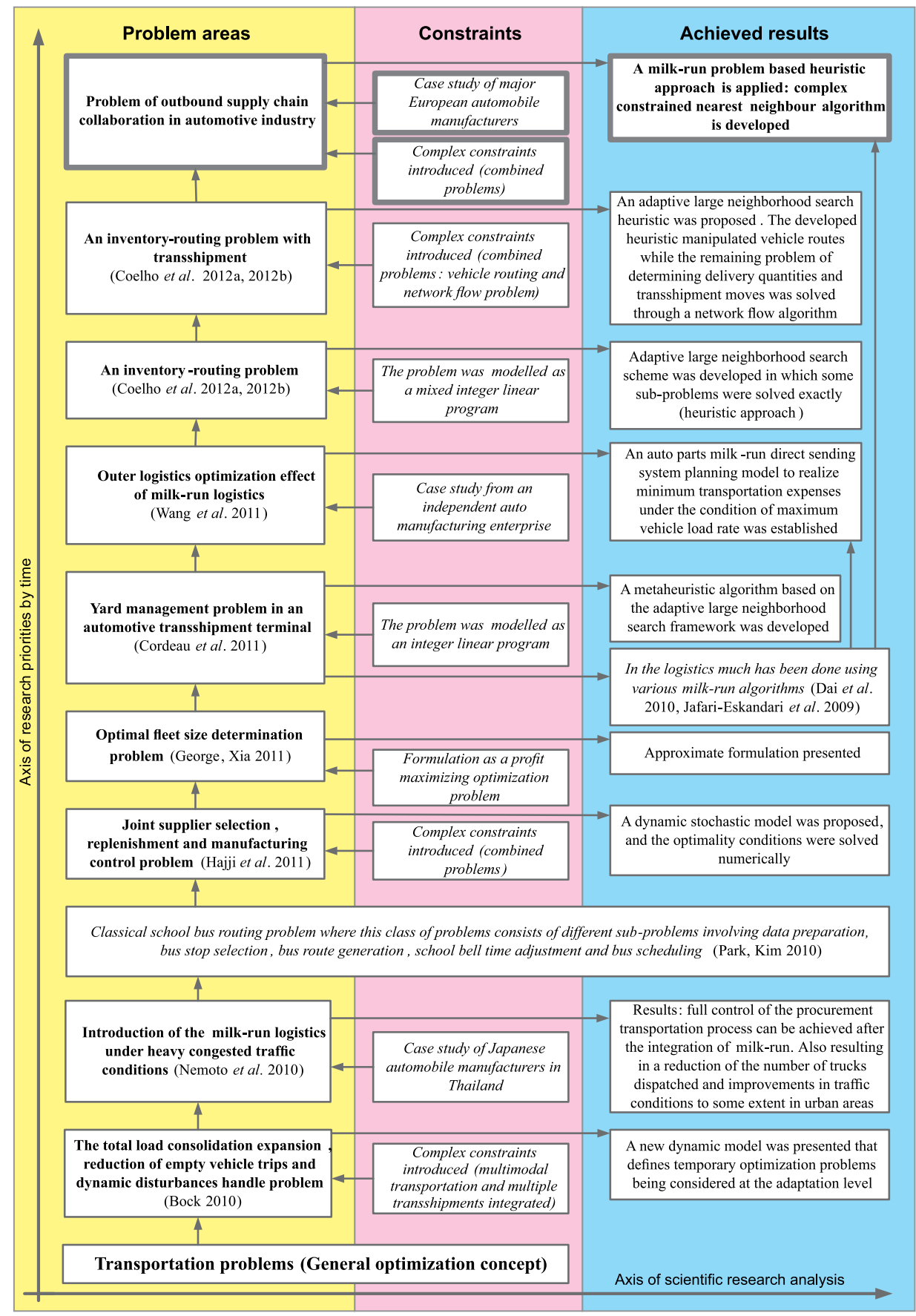

Fig. 1. Overview of solution methods of specific transport problems

railway transport, which has a characteristic high loading factor and a better price ratio, may be a superb alternative for reducing the disbalance of cargo flows and serve the badly-connected transport regions in large distances. Geographical, road infrastructure and time irregularities that may occur in the distribution network can be best corrected by the use of road transport; however, it is important to consider possible alternatives in respect of the whole network or the logistics chain.

Automobile roads currently account for haulage of $44 \%$ of all EU cargo, as compared to $39 \%$ of cargo transported in short sea shipping and $10 \%$ by rail (source: Eurostat - http://epp.eurostat.ec.europa.eu). The demand for road transport is highly affected by the following factors:

- traffic congestions;

- partial loading;

- empty running;

- driving restrictions;

- unbalanced cargo flows;

- cabotage restrictions;

- relatively low demand for railway transport;

- diversion of planned cargo flows.

Types of transport that can carry an extremely large amount of cargo at a time, such as the sea or railway transport are not integrated enough in the cargo flow 
distribution infrastructure. These types of transport should get as much attention as possible in order to diminish the negative factors of the logistics system. Constantly growing fuel prices, rising taxes for road infrastructure and pollution - these are the macro measures that constantly boost transport costs, at the same time encouraging industries and logistics operators to pay more attention to optimization of transport processes and reduction of resources used. Practical implementation of some logistics solutions aimed at reducing the demand for transport resources have yielded positive results in certain regions. For example, modernization of port infrastructure and doubling the number of such ports from 3 to 6 in Spain has allowed reducing the demand for road transport to $29 \%$.

\section{Road Transport Scenario for Emerging Outbound Supply Chain in Automotive Industry}

A road transport scenario with certain restrictions is formulated in order to identify certain problems of the distribution network, such as badly-connected transport regions, empty running factor and determine the demand for existing road transport resources (Fig. 2).
According to the scenario, the flow of automobile distribution will be covered by road transport only.

The production distribution flow is designed in a way that every automotive factory pushes its production to every country included in the model in line with the intensity of pull. However, stable transportation or delivery cannot be guaranteed due to different traction of terminals in different countries or varying intensity of productivity of plants. Therefore, the model requires consideration of the time factors of loading upon the vehicle and transportation from the plant to the terminal. One of the conditions is that the finished vehicle output of every factory in the model is transported to all countries, i.e., the production is not ascribed to a specific realization market. The model of transport flows is based on the 2009 data of finished vehicle production and sales (Fig. 3).

\section{Development Principles of Terminals' Network and Determination of Loading Factor}

The size of demand of a particular terminal is determined by infrastructure parameters of every terminal. The accepted condition is that 1 vehicle is provided

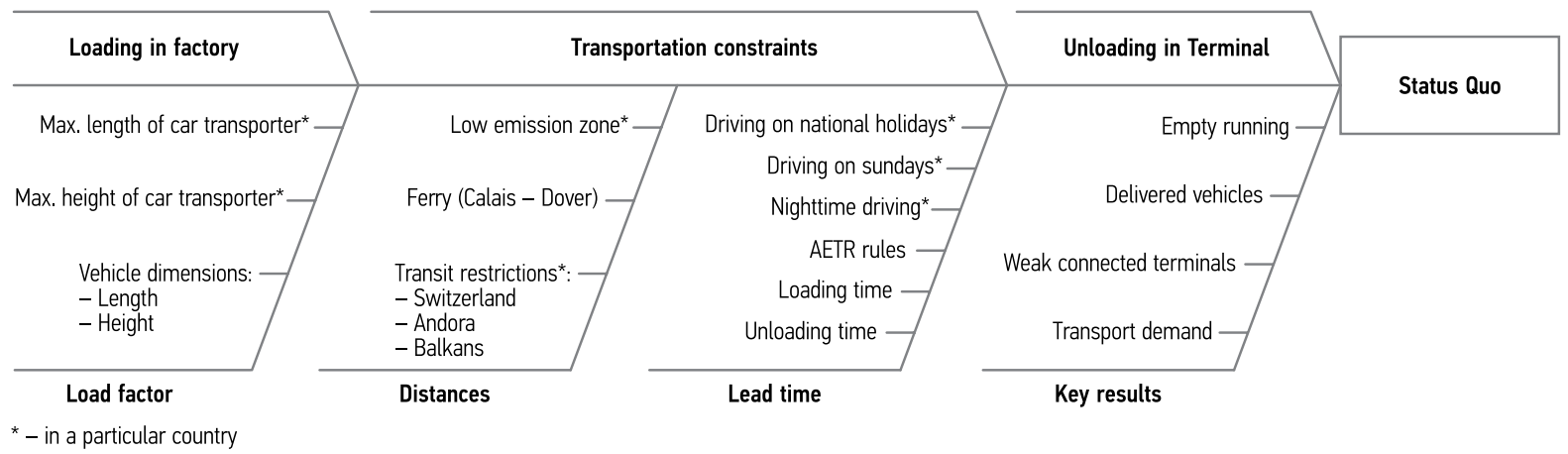

Fig. 2. Outbound scheme with particular limitations and the key results of the road transport scenario

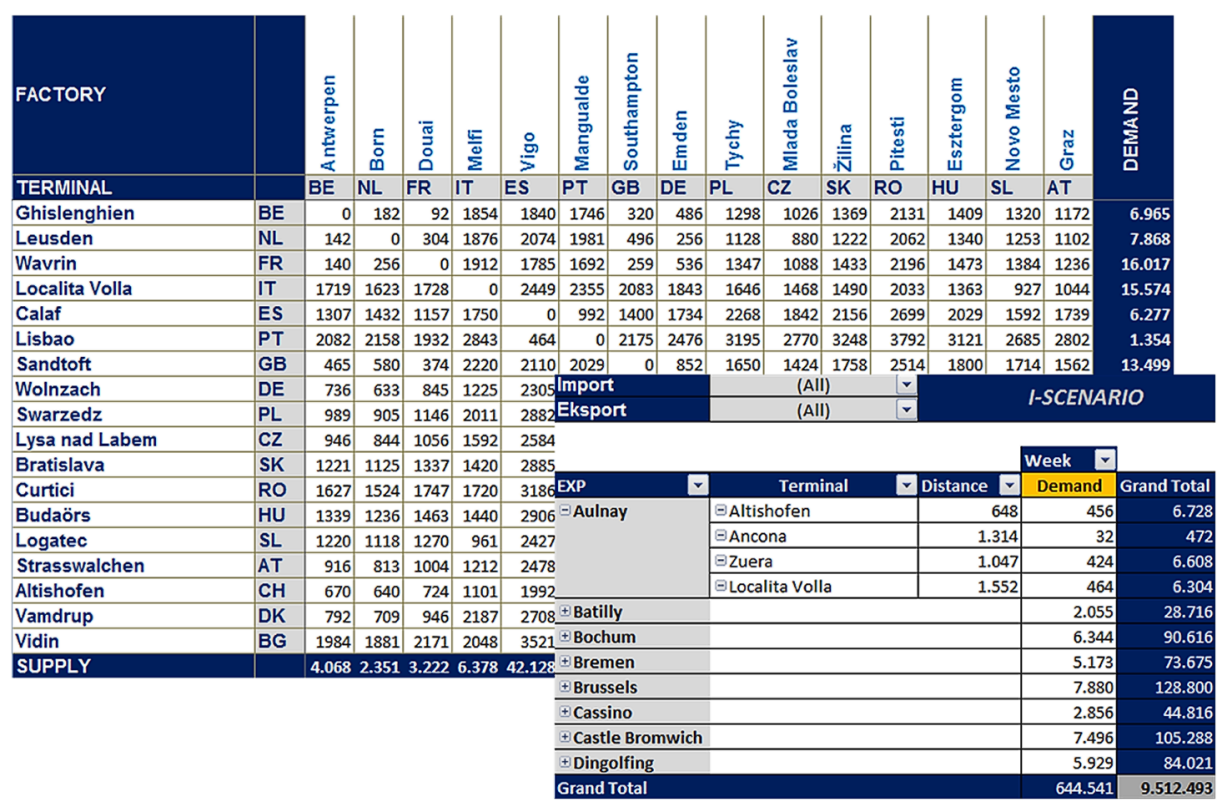

Fig. 3. A fragment of calculations by road transport scenario 
$20 \mathrm{~m}^{2}$ storage area in a terminal. Imported automobiles are distributed in proportion to the size of terminals in square meters. In terms of square meters, a presumption is made that the size of terminals describes the intensity of automobile demand in the target region that hosts the terminal. The network of terminals is developed in a way that all vendors in the territory are located within a $250 \mathrm{~km}$ radius from the nearest terminal. A terminal is the destination point; therefore, the model will not cover transportation between terminals. Pull of terminals of an importing country is reflected in the infrastructure capacity of the terminals, i.e., the number of automobiles they can accept and warehouse at a time. In the model, pull of cargo flow by terminals is identified by the proportion of volumes of production sold in different countries and overall infrastructure capacity of all terminals. After unloading, a vehicle is to be directed to the nearest factory with the largest pushing coefficient, i.e., to the nearest point that can offer a full load. Production of every factory has a relevant loading factor between 3 and 9, which depends on the measures of finished vehicles and in the light of the maximum allowed length and height of a loaded car transporter in the country where the factory is located.

\section{Transportation Restrictions}

Freight geography is also subject to certain traffic restrictions, i.e., cargo is transported from Northern Italy to Germany and back bypassing Switzerland due to the severe environmental requirements applied for cargo trucks crossing the Alps. As Switzerland is involved in the model, the country will be the import country, not a transit country. Transit will also be restricted via Andorra and the Balkans. The United Kingdom is linked with the continental Europe through the Eurotunnel or ferry lines across the English Channel. According to the scenario, car transporters will travel to the United Kingdom by ferries via the ports of Calais (France) and Dover (England).

Due to restrictions of work and rest time for drivers (AETR rules), a car transporter can cover $500 \mathrm{~km}$ a workday. The cargo flow model is based on ideal driving conditions, without consideration of stretches of roads under repairs, accidents, traffic congestions, technical breakdowns and other factors that may affect the speed of transportation. Considering restrictions for freight traffic at night, Sundays and public holidays, a condition is envisaged that car transporters will work 5 days a week. An expert survey revealed that a car transporter is fully loaded within an average of 2 hours and unloaded within 1 hour.

\section{Calculations}

In spite of various methods and techniques being actively and continuously developed for solving different combinatorial optimization problems as transport models is still an open-end problem in most practical situations. Such methods and techniques can deliver substantial benefits by improving productivity, utilization of resources and time constraint management at different levels of decision-making and manufacturing processes. Also transport problems can pose extremely complex combinatorial optimization problems. In general the main problem consists of finding the numbers of transport vehicles that minimize the total transport time and are consistent with the restrictions of produced vehicle supply in nodes $i$ and demand in node $j$. The same problem can be formulated as a comparison of the transport model with the vehicle management model:

- departure node $i$ - vehicles production period $i_{0}$ in node $i$;

- destination node $j$ - consumption period $j_{0}$ in node $j$;

- supply in node $i$ in time $t_{i j}$ - production output in node $i$ during period $i_{0}$;

- demand in node $j$ in time $t_{j i}$ - volume of sales in node $j$ during period $j_{o}$;

- vehicles transport time from node $i$ to node $j, t_{i j}$ or from $j$ to $i, t_{i j}$ - single vehicle transport time during the period between periods $i_{0}$ and $j_{0}$.

A single vehicle transport time $t_{i j}$ between periods $i_{0}$ and $j_{0}$ is formulated as period $t_{i j}$ or $t_{j i}$. It is used to evaluate the round trips between nodes $i$ and $j$ and back. The transport model has $m+n$ inequality restrictions on the mathematical transport model. Because transport models are always balanced (sum of all supplies is equal to the sum of all demands), the total number of inequalities and basic variables must be $m+n-1$. The problem is formulated as a transport model. The main parameters are presented as:

$-m$ is the number of production factories (departure nodes);

- $n$ is the number of warehouses (destination nodes).

Before presenting the objective function, some technical definitions are as follows: the transport problem is partially defined on a local graph $G=(V, A)$ for each separate vehicle transport by a single truck for separate periods $t_{i j}$, where $V$ is the set of nodes $(m, n)$ and $A$ is the set of single vehicle transport times. The arcs connecting the nodes of departure to the destination nodes match the pre-defined routes of trucks. The $\operatorname{arc}(i, j)$ that connects the departure node $i$ with the destination node $j$ is described by several additional parameters:

- $t_{i j}$ is the time of a single vehicle transport from node $i$ to node $j$;

- $t_{j i}$ is the time of a single vehicle transport from node $j$ to node $i$, empty mileage for every reverse trip;

- $x_{i j}$ is the number of transported vehicles from node $i$ to $j$;

- $x_{j i}$ is the number of transported vehicles from node $j$ to $i$, it is the leftover of vehicles being transported back;

- $a_{i}$ is the number of vehicles in node $i$ (at time $t_{j i}$ and $t_{i j}$; ;

- $b_{j}$ is the number of vehicles in node $j$ (at time $t_{j i}$ and $t_{i j}$ ). 
The asymmetric properties of the problem are described by the vehicles leftover being transported further to nodes $i$, when $t_{j i} \cdot x_{j i}>0$. An assignment based double-index integer formulations $\rho_{i j} \in\{1,0\}$ are used to define the binary variables $\{1\}$ or $\{0\}$ used in the description of the objective function where variable $\{1\}$ is assigned if the distance $(i, j)$ has been used and $\{0\}$ otherwise, and is used for the reverse distances $(j, i)$ that fully eliminate the asymmetric properties of the model. The objective function $Z_{1}$ for each individual trip is formulated as Eq. (1):

$$
\begin{aligned}
& \min Z_{1}=\sum_{i=1}^{m-1} \sum_{j=1}^{n} t_{2 \cdot i-1,2 \cdot j-j} \cdot x_{2 \cdot i-1,2 \cdot j-1} \cdot \rho_{2 \cdot i-1,2 \cdot j-1}+ \\
& \sum_{i=1}^{m-1} \sum_{j=1}^{n} t_{2 \cdot i, 2 \cdot j} \cdot x_{2 \cdot i, 2 \cdot j} \cdot \rho_{2 \cdot i, 2 \cdot j} \\
& \text { subject to: } \\
& \sum_{i=1}^{m} \rho_{i j}=1 ; \\
& \sum_{j=1}^{n} \rho_{i j}=1 \\
& \sum_{i=1}^{m-1} \rho_{i j}=1 ; \\
& \sum_{j=1}^{n-1} \rho_{i j}=1 ; \\
& \sum_{i \notin S} \sum_{j \notin S} \rho_{i j} \geq 1, i=1 \ldots m, j=1 \ldots n \\
& \sum_{j \notin S} \sum_{i \notin S} \rho_{j i} \geq 1, \forall S \subseteq V \backslash\{1\}
\end{aligned}
$$

Sub-tour elimination constraints Eqs $(6,7)$ that impose connectivity requirement for the solution, i.e. prevent the formation of sub tours of cardinality $S$ not including the departure nodes $i$ and $j$. Such problem can be solved using many heuristic approaches. The objective function is different when the next node after the supply node is the same supply node or when the next node after the demand node is the same demand node. Such scenario is when the supply in separate nodes is greater compared to the demand in route nodes. Then the vehicles leftover transport is evaluated. The evaluation of times $t_{i j}$ or $t_{j i}$ is done and compared to $a_{i}$ and $b_{j}, a_{i}\left(t_{i j}\right)-x_{i j}\left(t_{i j}\right), a_{i}\left(t_{j i}\right)-x_{i j}\left(t_{j i}\right), b_{j}\left(t_{i j}\right)-x_{i j}\left(t_{i j}\right)$. The next node is then picked, either supply or demand. When using the method of potentials in the evaluation of the times and the objective functions additional time period's dependencies are introduced making the proposed static transport model more dynamic in terms of production and sales periods. Here the potentials $u_{i}$ and $v_{j}$ are introduced for each node $i$ and $j$. For each single period value $x_{j i}$ the formulation are: $u_{i}+v_{j}=t_{i j}$ and $u_{i}+v_{j}=t_{j i}$. For the initial trip $(i, j)$ the potential is $u_{i}=0$ and for the initial trip $(j, i)$ the potential is $v_{j}=0$ with the forward computation of the potentials in further periods. Then the objective functions $Z_{2}$ and $Z_{3}$ for such scenario are formulated as Eqs $(8,9)$ :

$$
\begin{aligned}
& \max Z_{2}=\sum_{i=1}^{m-1} a_{2 \cdot i-1}\left(t_{i j}\right) \cdot u_{2 \cdot i-1}\left(t_{i j}\right)+ \\
& \sum_{j=1}^{n} b_{2 \cdot j-1}\left(t_{j i}\right) \cdot v_{2 \cdot j-1}\left(t_{j i}\right) ; \\
& \min Z_{3}=\sum_{i=1}^{m-1} a_{2 \cdot i}\left(t_{j i}\right) \cdot u_{2 \cdot i}\left(t_{j i}\right)+ \\
& \sum_{j=1}^{n} b_{2 \cdot j}\left(t_{j i}\right) \cdot v_{2 \cdot j}\left(t_{j i}\right),
\end{aligned}
$$

subject to:

$$
\begin{aligned}
& u_{i}+v_{j} \leq t_{i j} ; \\
& u_{i}+v_{j} \leq t_{j i} .
\end{aligned}
$$

where: $u_{i}$ is the random dual variable that matches the limitations of supply in node $i$ in time $t_{i j} ; v_{j}$ is the random dual variable that matches the limitations of demand in node $j$ in time $t_{i j}$.

Values $t_{i j}$ and $t_{j i}$ are formulated as $t_{i j}=t_{i j}+f$ and $t_{j i}=t_{j i}+f$ respectfully. Additional parameter $f$ is added to compensate the inequalities. It should be noted that such addition has no impact on the optimum values $x_{j i}$. The Nearest Neighbour (NN) algorithm is a very fast and simple heuristic solution method for transportation problems that provide the initial optimization solution in local TSP using the minimum vehicle transport time and the supply and demand among the nodes. The NN algorithm starts with an arbitrarily chosen departure node $i$ as partial tour and the destination node $j$, and the same with reverse. If node $j$ or $i$ is already contained in the partial tour ties are broken arbitrarily. That way, it could be suggested that it is possible to get a near optimum initial solution with the given algorithm at the same period of time for all trips.

The calculations were made for an interval of one week and the supply was equal to the demand. In total 103132 vehicles were delivered within a week. Distribution of this number of vehicles was performed by 6,803 car transporters. Empty running accounted for $9.58 \%$ of the total mileage, as compared to about $27 \%$ empty running reported by European cargo road transport in 2011, according to Eurostat. The initial results highlighted the terminals with weak connections where empty running included intervals of $250 \div 500 \mathrm{~km}$ (Fig. 4). The condition of restrictions envisaged that a car transporter covers $500 \mathrm{~km}$ a day, however, calculations showed that the average distance covered by one vehicle was $462 \mathrm{~km} /$ day. This was due to the density of loading, i.e., when the truck had to be loaded more than once a day, and ferry transport to the United Kingdom.

To justify the statement about absence of a unified method for solving specific transport problems, the data of the scenario described in the article are imported into the TORA Optimization System software intended to solve classic transport problems. The results revealed the shortest routes for different specific restrictions applying to some zones in the EU only. Consequently, the longest distances to the terminals in destination countries and the most expensive terminals were not included 


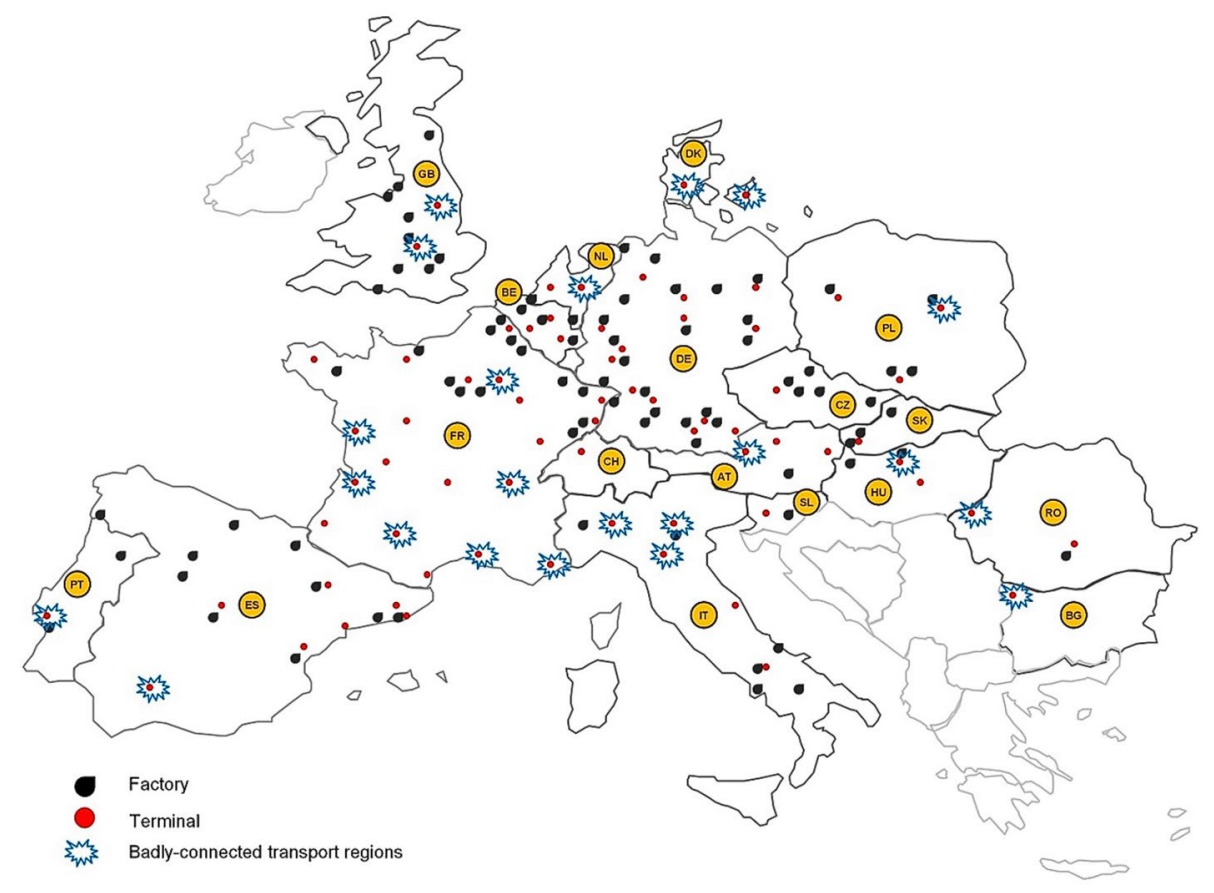

Fig. 4. Examined Transport model concept with badly-connected transport regions

into the calculations. Given the main condition of the problem that production supply in a factory equals the production demand in terminals, uneconomic terminals cannot be left out of the calculations, as this would lead to supply exceeding the demand, and target markets will not be supplied with the production they need.

\section{Conclusions}

In spite of various methods and techniques being actively and continuously developed for solving different combinatorial optimization problems as transport models, it is still an open-end problem in most practical situations. Such methods and techniques can deliver substantial benefits by improving productivity, utilization of resources and time constraint management at different levels of decision-making. As one may notice, complex solutions for the proposed transportation problems are applied more effectively than the classical ones. On the other hand, when these problems become too difficult to be solved because of the many additional real-life constraints (computation complexity), then the everyday simple and fast solutions like NN algorithms are often presented as the best choices for practitioners.

A transportation problem for the road transport scenario was developed in the light of disbalance of finished vehicle output volumes, transportation time and infrastructure restrictions. After identification of the need of existing transport resources, the next phase of optimization is to come up with measures that would help reduce the use of existing transport resources. To achieve the objective, sea and railway transport will be integrated into the existing model of transport flows, as sea and railway transport features a higher loading fac- tor. However, when formulating a multimodal transport scenario, one must consider the fact that efficiency of use of one type of transport cannot be achieved at the expense of other types of transport.

The mathematical transport flow model described in the article makes it possible to identify key problems of the transport network in the light of transportation time and the amount of automobiles carried in accordance to set restriction functions $\min \sum t_{i j} \cdot x_{i j}$, $\min \sum t_{j i} \cdot x_{j i}$. After establishing problem points of the selected road transport that do not correspond to the terms and conditions of the task restrictions, alternative types of transport can be incorporated. For example, railway transport is used in cases of the accumulation of excess amounts of production that cannot be handled by road transport, as well as for distances that are longer than $1000 \mathrm{~km}$ or points where road transport needs to drive more than $500 \mathrm{~km}$ to the loading site.

\section{References}

Ba, S.; Fang, W.; Bao, J.; Liu, L. 2009. Research on the value chain extension of automotive industry based on the mode of industrial and financial capital combination, in 2009 International Conference on Information Management, Innovation Management and Industrial Engineering (ICIII 2009), 26-27 December 2009, Xi'an, China, Vol. 3, 526-530. http://dx.doi.org/10.1109/ICIII.2009.437

Bock, S. 2010. Real-time control of freight forwarder transportation networks by integrating multimodal transport chains, European Journal of Operational Research 200(3): 733-746. http://dx.doi.org/10.1016/j.ejor.2009.01.046

Coelho, L. C.; Cordeau, J.-F.; Laporte, G. 2012a. Consistency in multi-vehicle inventory-routing, Transportation Research Part C: Emerging Technologies 24: 270-287.

http://dx.doi.org/10.1016/j.trc.2012.03.007 
Coelho, L. C.; Cordeau, J.-F.; Laporte, G. 2012b. The inventoryrouting problem with transshipment, Computers and Operations Research 39(11): 2537-2548.

http://dx.doi.org/10.1016/j.cor.2011.12.020

Cordeau, J.-F.; Laporte, G.; Moccia, L.; Sorrentino, G. 2011. Optimizing yard assignment in an automotive transshipment terminal, European Journal of Operational Research 215(1): 149-160. http://dx.doi.org/10.1016/j.ejor.2011.06.008

Dai, Y.; Xia, W.-H.; Ge, H.-L. 2010. Study on multi-depot vehicle scheduling problem based on milk-run model, in 2010 International Conference on Optoelectronics and Image Processing (ICOIP), 11-12 November 2010, Haiko, Hainan, China, Vol. 2, 444-448. http://dx.doi.org/10.1109/ICOIP.2010.12

George, D. K.; Xia, C. H. 2011. Fleet-sizing and service availability for a vehicle rental system via closed queueing networks, European Journal of Operational Research 211(1): 198-207. http://dx.doi.org/10.1016/j.ejor.2010.12.015

Hajji, A.; Gharbi, A.; Kenne, J.-P.; Pellerin, R. 2011. Production control and replenishment strategy with multiple suppliers, European Journal of Operational Research 208(1): 67-74. http://dx.doi.org/10.1016/j.ejor.2010.08.010

Holweg, M.; Miemczyk, J.; Williams, G. 2001. The 3DayCar Logistics Study: how to Organise Automotive Logistics in a Build-to-Order Environment. 81 p. Available from Internet: http://www.3daycar.com/mainframe/publications/library/ Logisticsrep.pdf

Jafari-Eskandari, M.; Sadjadi, S. J.; Jabalameli, M. S.; BozorgiAmiri, A. 2009. A robust optimization approach for the Milk Run problem (an auto industry supply chain case study), in 2009 International Conference on Computers and Industrial Engineering: Proceedings, 6-8 July 2009, Troyes, France, 1076-1081. http://dx.doi.org/10.1109/ICCIE.2009.5223541

Nemoto, T; Hayashi, K.; Hashimoto, M. 2010. Milk-run logistics by Japanese automobile manufacturers in Thailand, Procedia - Social and Behavioral Sciences 2(3): 5980-5989. http://dx.doi.org/10.1016/j.sbspro.2010.04.012

Park, J.; Kim, B.-I. 2010. The school bus routing problem: a review, European Journal of Operational Research 202(2): 311-319. http://dx.doi.org/10.1016/j.ejor.2009.05.017

Sturgeon, T. J.; Memedovic, O.; Van Biesebroeck, J.; Gereffi, G. 2009. Globalisation of the automotive industry: main features and trends, International Journal of Technological Learning, Innovation and Development 2(1-2): 7-24. http://dx.doi.org/10.1504/IJTLID.2009.021954

Tang, L.; Xu, H.; Nong, X. 2010. Automotive supply chain logistics cost management research, in 2010 International Conference on Computer and Communication Technologies in Agriculture Engineering (CCTAE 2010), 12-13 June 2010, Chengdu, China, Vol. 2, 343-346. http://dx.doi.org/10.1109/CCTAE.2010.5544198

Wang, L.-F.; Kong, F.-S. S.; Cao, J.-H.; Wang, Y.-C. 2011. Research on the application and optimization countermeasures of auto parts milk-run logistics mode, in 2011 IEEE 18Th International Conference on Industrial Engineering and Engineering Management (IE\&EM), 3-5 September, 2011, Changchun, China, Part 1, 195-200.

http://dx.doi.org/10.1109/ICIEEM.2011.6035138 